PAPER

\title{
What is it to do good ethics?
}

\author{
Daniel Callahan
}

\section{Correspondence to Professor Daniel Callahan, The Hastings Center, 21 Malcolm Gordon Road, Garrison, NY 10524, USA; Callahand@thehastingscenter. org}

Received 2 September 2014 Revised 30 September 2014 Accepted 1 October 2014

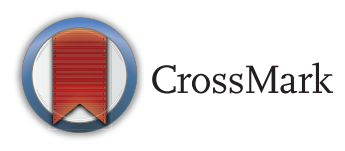

To cite: Callahan D. J Med Ethics 2015:41:68-70.

\begin{abstract}
Much of my work in bioethics over the years has been throwing off ethics as pursued in the analytical tradition. I believe the field should steer clear of the rigid style of hyper-rationalist ethics and a reduction of ethics to a search for rules and principles. It should be open to a full range of influence, in style and substance, of literature, history and the social sciences. It should take in the full range of human life, individual and social.
\end{abstract}

I must say at the outset where I started down my road to a career in ethics. My serious introduction to moral philosophy was as a graduate student at Harvard in the late 1950s. The department had then only recently made a sharp turn to analytical philosophy, imported from Oxbridge. I was drawn to philosophy in my undergraduate days by Plato and Aristotle, and Socrates was my model. He went about the Agora asking hard questions on important topics, getting himself in trouble. When I once mentioned my attraction to Socrates, one of my professors responded by saying in effect, and condescendingly, that 'we don't do that kind of thing here any more'. It was frequently said in the department that the history of philosophy was really not philosophy at all. Plato and Aristotle got no attention.

The leading professor of moral philosophy in the department at that time was Roderick Firth. $\mathrm{He}$ espoused the 'ideal observer' theory of ethics, that is, the viewpoint of some perfectly situated observer who is able to see a moral problem from all angles, and in light of everything relevant, and then come to a perfectly rational decision. The implication of the theory was that we should do likewise, but with no guidance about how to achieve that elevated state. But we were taught well to pounce on major terms in ethics with exhaustive and exhausting analytical force. What could be a better target for analysis than the word 'good'?

Had I taken all that training with the requisite seriousness, I would spend the remainder of this essay examining 'good' in as in 'good ethics', turning it over a dozen or more times, lamenting my lack of space to go on, helpfully avoiding altogether the need to answer the question. That kind of paper could probably make it through peer review in some journals, but I will refrain from showing my full skills at doing that, and trust I will be held to a less demanding standard. Yet I can't avoid doing a bit of it in trying to answer the question, 'what is it to do good ethics?'

My problem in answering it is threefold. First, as I came to write about many different kinds of ethical issues over the years, many of a complicated kind, no ethical theory seemed to fit well for any of them; and I gradually moved away from an interest in ethical theory itself, a major preoccupation in the early years of bioethics. How could bioethics as a new discipline be credible if it was not grounded in a theory, as is good science? It turned out we could get by, and an early anxiety about theory faded away for me and many others. Second, I had a strong background in college and from other sources of knowledge in literature, history, psychology and social theory. They revealed the richness and variety and sometimes craziness of human life, individual and collective. That complexity served as an antidote to the hyper-rationality pretensions of analytical ethics. Third, I became increasingly interested in what I think of as the ideological and cultural forces that help shape what we make of life and our place in it. Finally, having set the stage, I can get to the question of what it means to do good ethics and what I believe has to be an essential question that should be a part of it: what kind of person does one have to be to do good ethics.

\section{THE INADEQUACY OF ETHICAL THEORY}

Those working on global warming often use the phrase 'wicked problems'. It is meant to describe issues where the science is uncertain, the proper relationship between science and policy is controversial, the time for action is short, the relevant actors bring to the table different values and the long-term consequences are uncertain. The strategy least likely to be helpful with such problems is to find reductionist ways to reduce moral problems down to a choice between utilitarian and deontological theories.

My favourite book on ethics (although never advertised as such) is the 1987 book, The Making of The Atom Bomb, by Richard Rhodes. ${ }^{1}$ It carefully lays out how the technical difficulties of making such a deadly weapon were overcome, but no less attention is paid to the ethical qualms and arguments along the way by the scientists inventing it. A good case can be made that making the bomb was the most important moral decision in history, one that haunts us to the present, with pressure to limit making them, stopping other countries from joining the nuclear arms race and to eliminate them altogether.

\section{THE VARIETIES OF HUMAN EXPERIENCE}

Another influential book for me was by the historian Bruce Kuklick, The Rise of American Philosophy. ${ }^{2}$ The title is misleading in two respects. It was actually a book about the history of the Harvard philosophy department, taken to be a bellwether of the field itself. And it well could have been titled The Decline of American Philosophy, much closer to the book's thesis. His contention was that the movement away from a wide-ranging, 
intellectually rich and adventurous field in the late 19th century to a narrowly arid and professional one by the mid-20th century was a loss all around. Those early years marked the separation of philosophy from its earlier association with psychology, to become a stand-alone discipline.

William James, a towering figure in those years, continued to straddle both of those fields. But he was also joined by some illustrious colleagues, including Charles Sanders Peirce, Josiah Royce and George Santayana. All of them were to be distinguished by two differences from those who came after them as the field changed. One of them was their comfort in exploring every facet of human life, literature, history and religion most notably; they observed no disciplinary boundaries. The other was that they wrote for the educated public, not for their peers or professionals in the field. They remain for me my models, and it is easy to include Socrates in their company (even if Plato did the writing). As it happened as well in the early 1980 s psychology was rediscovering the role of the emotions in human consciousness. My wife, a psychologist, wrote a book on that topic, The Role of Reason and Emotion in Moral Decision Making. ${ }^{3}$ It was stimulated, in part, also by many conferences at the Hastings Center, where she heard many philosophers treating the emotions as dangerous obstacles to reason, not their partner as psychologists were discovering-and both forgetting that Aristotle came to that conclusion long ago.

Those characteristics resonated for me. My interests in the full range of the humanities and social sciences, together with my desire to reach an audience beyond the academy, inoculated me against (to use a phrase whose provenance I can't recall), the notion of reason as a 'a well-lighted, clean room'. A lot of the worst people in history, take your pick, were horribly and efficiently rational in pursuing their goals. As someone once commented on a notorious dictator, 'no one said he was stupid, but that he was cruel and murderous.' People like that just start from wrong premises, or distortions of good ones. Unfortunately, ethics has never been good in helping us to find first principles or solid insights about how to find a good insight. All proposed starting points seem to invite an infinite regress of justification.

As individuals, we are complex, with reason and emotion closely intertwined; and often with conflicted emotions, alleged rational decisions usually open to challenges by other rational judgements. We can also have intuitions of unknown psychic origins, sometimes solid, sometimes faulty-and yet sometimes full of insight. The humanities are rich sources of insight, revealing our personality differences, and helping us to distinguish between self-deception and good moral judgement. As social creatures, the social sciences, history and literature inform us how to understand our life with others, how they shape us and we shape them, how people in anonymous crowds or different social groups can be led to do good or bad things.

One of the worse debates of late among philosophers, I believe, has been on how to create more moral people, by scientific or other means. In the 1970s, there was a short-lived debate on the proposal by a prominent psychologist about the need to invent a pill that would eliminate human violence. Apart from the fact that no one could even imagine how to create such a pill, the main obstacle was in trying to find a bright line between the violence that might be valuable in acceptable self-defence and unacceptable aggressiveness and violence, and to engineer one and not the other. Much of what is bad about human behaviour is intertwined with what is good. Effective and praised politicians have often been bad or indifferent fathers or unfaithful spouses. Otherwise peace-loving people can be caught up in harmful social movements. Not all Nazi soldiers were cold-blood killers and not all who were started out that way; not all Germans sympathised with the Nazis, even if they looked the other way in face of atrocities or out of fear of harm if they spoke out against them. But the philosophical exchange on moral enhancement has not so far as I know made use of literature and history to better understand human nature. The debate comes across as narrow and flat.

\section{THE IMPACT OF CULTURE, IDEOLOGY AND CLASS}

It did not take me many years working with bioethicists, whatever their discipline, to discern how the positions they took on controverted issues reflected in disturbing ways the effects of their culture and ideology on their judgements. They were too often predictable in ways that belied their claimed rationality. Alasdair MacIntyre made a good case in Whose Justice? Which Rationality? that we can only make moral judgements from the perspective of our own culture. ${ }^{4}$ There is no place to stand to pass judgement from some neutral perspective. There can be no ideal observer. But he avoids the sheer relativism of that approach by arguing that one can argue from within a culture in a critical way and move beyond it if there is the freedom to do so. Not everyone, I have found, tries hard to do that. They remain in lock step with their class, or religion (or rejection of religion), or professional group, or national, ethnic or gender background. And I suppose that might apply me, if I could determine to which tribe I belong.

It is a delicate matter to get out of such traps. It is much harder to turn a critical eye on oneself and one's friends and colleagues than on outsiders. One of the hardest struggles of my career has been to get those in medicine and healthcare to critically examine the concept of medical progress and that of the goals of modern medicine shaped by it. Progress and the technological innovation that goes with it are taken to be selfevident values, to be defended and advanced, at the heart of modern medicine. When an allocation of scarce resources is needed for hard-to-afford healthcare, the standard response is to devise an organisational or managerial response, and for ethical procedures of an impersonal kind to be used in cases of dilemmas of justice. But many of those dilemmas arise because of expensive new technologies. One thing modern medicine is very good at is its ability to keep elderly sick people expensively alive for a longer and longer time, while not extending health so much as extending disability and the process of dying.

I believe the real trouble arises because of a progress-driven and technology-driven model of medicine that is its basic or core value. Everything else can be challenged, but not that. There is no such thing as enough medical progress or technological innovation; just more and more is wanted, by the public, by doctors, by medical researchers and of course by all the industries selling those devices and drugs that make the intensive care unit (ICU) such a temple of progress. Is this what medicine ought to be all about?

The time has come, and really long past, when the goals of medicine-and not just the means to make its progress-driven agenda work more fairly and efficiently-need to be examined. The idea that research on nuclear weapons, which did after all once win a war, should continue indefinitely to improve their deadliness and efficiency is (at least I hope) no longer an ideal. It was not always that way. Oppenheimer, we should recall, unsuccessfully struggled against hydrogen bomb research to supersede the atom bomb, and lost his government security clearance in great part because of that opposition. But the medical progress research drive knows no limits. A check of major medical data bases on the concept of medical progress turned up little, and I know of nothing written in medical ethics journals. That dearth supports my perception that the need for 
medical progress has the status of a dogma, not to be challenged. But I firmly believe that unless we take on medical progress for assessment and change, the problem of medical care in our aging societies will just get worse and worse. More broadly, a constant hazard for medical ethics will be to go along with the crowd and continue to fail to say that every technological innovation should have to pass a test of whether it will be good for humans and not dodged by assigning it to an institutional review board (IRB) committee, whose aims are to assess the means to carry out the research, not the goals of the research. The occasional warning over the years to avoid captivity by the medical establishment has not always been heeded. Bioethics has been more about means than about ends.

\section{WHAT KIND OF PERSON OUGHT ONE BE TO DO GOOD ETHICS?}

By now I have said what I want to say about what it means to do good ethics. For me that meant uprooting much that I had learned years ago in graduate school, both in substance and in style. In substance, it meant if not wholly abandoning ethical theory, at least taking it with more than a grain of salt; nothing less than a cup full will do. In style, it meant rejecting the cool, detached analytical way of talking and thinking about ethics in favour of a greater immersion in human history and experience. It wasn't just a matter of formulating good arguments and clever responses to those of others. Bioethics requires getting into the minds, emotions and culture of those who will actually have to make hard treatment decisions with individual patients, and doing the same with legislators and government officials, whose decisions can matter enormously for healthcare systems and thousands of people.

Here is a question I often put to fellow philosophers: Does one have to be a good person to do good ethics? The analytically inclined would usually respond with a quick and firm 'no'. Ethics is a rational enterprise, in no more need of virtuous practitioners than logic, chemistry or statistics. Only brains and smart counterarguments matter. Others were not so sure. One of the early philosophers of a different breed working with the Hastings Center in our first years was Hans Jonas. He was a German Jew who studied with Martin Heidegger and Hanna Arendt. He joined the British army during the war, coming to the USA after that. He did not talk about phenomenology or Hegel or about other continental ideas. He just talked ordinary talk, his considerable breadth of knowledge and familiarity with war and suffering shining forth, his integrity and goodness as a thoughtful person giving his words a stamp of authenticity. Unanimously, the nonphilosophers considered him a 'real' philosopher, not the kind they ordinarily heard from at gatherings of the ethics clan.

In the USA, recently, there has been a burst of discussion about the question, 'what makes a good doctor?' It is driven by a strong sense that being a doctor has changed, not always in a good direction: a bemusement with technology symbolised by doctors who spend more time during patient visits looking at their computer screens than the faces of those patients; by specialists who have no interest in patients as persons, only their malfunctioning organs; and by a new generation of doctors unwilling to make night house calls. A recent book, The Good Physician, by a physician, Barron Lerner, who is also a bioethicist and medical historian, is a comparison of his medical experience with that of his father. ${ }^{5}$ The father was very much old school, someone who put care of his patients above everything else in life, available to them day and night, and interested in their personal and family life-and wholly indifferent to patient autonomy. He regularly practised euthanasia without the consent of patient or family.

The son, educated in our contemporary medical culture, keeps more regular hours, and one in which respect for patient autonomy has become the dominant moral principle. Yet, the son has picked up a new breeze filtering in, questioning the dominance of autonomy. Maybe patient care is more complex than that and maybe autonomy is neither right nor possible with many patients. If that is so, then maybe medical ethicsthe main purveyor of autonomy since the 1970s-will be forced to tackle once more and head-on the question of what is good for patients, now deftly set aside with an emphasis on the rights of patients. Intended or not, a morality of choice as the essence of ethics that has been its recent dominant feature.

Of course the changes I hope for would bring us right back to where there are few 'clean and bright rooms' suffused with rationality. On the issue of ethical theory, I have been driven back to Aristotle's ethic, which comes down to virtuous citizens making good prudential judgements. Now, all we have to do is work out how those citizens can be helped in our times by those of us in ethics warming up to that demand in the only possible way: by our learning how to become virtuous people ourselves and helping others to make prudent decisions.

\section{Competing interests None.}

Provenance and peer review Commissioned; internally peer reviewed.

\section{REFERENCES}

1 Rhodes R. Making of the atomic bomb. New York, NY: Simon \& Schuster, 1987.

2 Kucklick K. The rise of American philosophy. New Haven, CT: Yale University Press, 1989.

3 Callahan S. In good conscience: reason and emotion in moral decision making. San Francisco, CA: HarperCollins, 1991.

4 Maclntyre A. Whose justice? Whose rationality? Notre Dame, IN: University of Notre Dame Press, 1989.

5 Lerner BH. The good doctor: a father, a son, and the evolution of medical ethics. Boston, MA: Beacon Press, 2014. 